\section{Iranian patients' attitudes to current and novel therapies: A patient directed survey}

\author{
Mahmoud Hadipour Dehshal, ${ }^{1}$ \\ Michael Angastiniotis, ${ }^{2}$ \\ Sachiko Hosoya, ${ }^{3}$ Fatemeh Hashemi \\ Bahremani, ${ }^{1}$ Mehdi Tabrizi Namini, ${ }^{4}$ \\ Androulla Eleftheriou ${ }^{2}$ \\ ${ }^{1}$ Charity Foundation for Special \\ Diseases, Tehran, Iran; ${ }^{2}$ Thalassaemia \\ International Federation, Nicosia, \\ Cyprus; ${ }^{3}$ School of Nursing at Narita, \\ Public Health Nursing, International \\ University of Health and Welfare, \\ Chiba, Japan; ${ }^{4}$ Iranian Blood \\ Transfusion Organization, Tehran, Iran
}

\begin{abstract}
Thalassemia is one of the important challenges of the health system in Iran. Recently the medicinal drug of luspatercept and gene therapy have opened new horizons for thalassemia treatment. The present article aims to evaluate the attitude of thalassemics in Iran about the new treatments.

In this research, data collection through the virtual space has been practiced. The patients were required to declare their opinion on the aforementioned treatments. Finally, 128 male and 204 female plus 1 who did not specify their gender answered the questions. The results showed that despite patients' positive attitude towards new treatments, their treatment experiences as well as the expenses of the new treatment practices are cause of concern. Moreover, the social problems like unemployment among thalassemics place impact on their perspective about treatment changes.

Based on the findings of the present research, providing patients with more information about new treatment regimen and making the their expenses compatible with the economic status of the developing countries would be effective in making the new treatments accessible to all eligible patients.
\end{abstract}

\section{Introduction}

Beta thalassaemia (BT) major is an inherited disease mostly prevalent in a region of the world known as the thalassemia belt. ${ }^{1}$ One of the countries located in the belt is Iran with close to $4 \%$ of its population being thalassaemia gene carriers. ${ }^{2}$ According to the latest reports, there are 18,918 registered cases of haemoglobinopathy in Iran out of whom 15,954 are beta thalassaemia major. ${ }^{3}$ For this reason, prevention and management of thalassaemia are considered to be among the priorities of the health system of the country. The thalassaemia prevention programme started in 1995 country-wide ${ }^{4}$ and in the year 2015 it succeeded in decreasing the predicted thalassaemia births by $90 \%{ }^{3}$ Regarding thalassaemia management, Iran has a good experience in ensuring adequate and safe blood and providing patients with free country-level treatment and care. However, there are complaints about the locally produced drugs concerning their quality and also about the difficult access to imaging and bone marrow transplantation centres. $^{3}$ Iranian success in thalassaemia prevention and treatment has led to the increase in the mean age of thalassaemics and realized the hope of thalassaemics living into their $4^{\text {th }}$ decade of life. ${ }^{3}$ Thalassaemics are participating in the arena of social life, and this strongly necessitates access to cure or to easier treatment regimens to facilitate better social integration.

In recent times, the news about the approval by regulatory agencies, i.e. European Medicines Agency (EMA) or Food and Drug Administration (FDA) in Western countries of innovative drugs for the treatment and cure of thalassaemia, including luspatercept ${ }^{5}$ and gene therapy, ${ }^{6}$ respectively, has led to increased expectations by both the health care professionals and in particular the patients. Given the importance of the patient's perspective in adopting new treatment strategies in thalassaemia, the present research aims to evaluate the viewpoints of patients with regards to these novel therapies.

\section{Materials and Methods}

In this research, a specific questionnaire was uploaded in Google form in which the individual's ID was requested to avoid the form being filled out multiple times by a single person. Access to the questionnaire was made possible from $18^{\text {th }}$ May 2020 until May $22^{\text {nd }} 2020$ and the link to the questionnaire was available to patients across the country through WhatsApp, Telegram, Instagram, and Facebook. The first response was provided 10 minutes after the questionnaire was made accessible and the last one was obtained 3 hours and 27 minutes before the deadline. The responses were processed by SPSS and the results were analysed.
Correspondence: Androulla Eleftheriou, Virologist, Executive Director, Thalassaemia International Federation, 31, Ifigenias Street, 2007 Strovolos, Nicosia, Cyprus.

Tel.: +35722319129.

E-mail: thalassaemia@cytanet.com.cy

Key words: Thalassaemia; patient perspective; patients point of view; novel therapies; gene therapies; luspatercept.

Acknowledgments: The Authors express their gratitude to Ms. Sara Yousefi Darestani for her valuable assistance and those thalassemia patients who have attended in the survey.

Funding: Charity Foundation for special diseases, Tehran, Iran and Thalassemia International Federation, Nicosia, Cyprus

Contributions: The authors contributed equally

Conflict of interests: The authors declare no potential conflict of interests.

Availability of data and materials: The data will be available within the article and its supplementary materials.

Ethics approval and consent to participate: The patients became aware of the purpose of this investigation and publishing the result and data without their name and ID. All of them accept terms and coditions before participating in the electronic questionnaire

Received for publication: 18 November 2020 Revision received: 11 January 2021.

Accepted for publication: 12 January 2021.

This work is licensed under a Creative Commons Attribution 4.0 License (by-nc 4.0).

Copyright: the Author(s), 2021

Licensee PAGEPress, Italy

Thalassemia Reports 2021; 11:9514

doi:10.4081/thal.2021.9514

\section{Results}

Out of 333 participants who answered the questionnaire, $128(38.4 \%)$ were male and $204(61.3 \%)$ female and 1 person had not indicated gender. The age related participation rate in the research is displayed in Table 1.

Out of 333 responses, $279(83.8 \%)$ were provided by thalassaemia major patients, 46 $(13.8 \%)$ by intermedia patients who were being transfused, and $8(2.4 \%)$ by intermedia patients who were not being transfused (Figure 1).

Most of the respondents (79\%) had a higher than high school diploma degree. The education status of participants is shown in Table 2. 
With regards to professional status, 223 (67\%) were unemployed, 43 (12.9\%) part time employed, $44(13.2 \%)$ full time employed, and $23(6.9 \%)$ were selfemployed.

The transfusion needs were appropriately addressed and reported by 285 (85.6\%) responders while the rest (14.4\%) responded and reported irregular transfusion intervals. The red cells provided to patients were processed as shown in Table 3.

Leukocyte-depleted blood was the red cell product most frequently provided to the patients.

Patients reported different experiences with regards to transfusion reactions; 218 reported experiencing alloimmunisation or other adverse transfusion-related reactions, grading them from severe to extremely severe reactions. The patient responses to this question are shown in Table 4.

From a total number of respondents, $149(44.7 \%)$ reported that they believe that blood units are cross-matched for only a small number of antigen groups.

Concerning the day care transfusion facility, $91(27.3 \%)$ of the patients reported that they are transfused at hospital-independent clinics with limited treatment facilities, $31(9.3 \%)$ reported that they are transfused at treatment centres with expertise in blood disorders, 198 (59.5\%) reported that they are treated in hospital haematology wards, and $12(2.6 \%)$ reported being taken care of in hospital emergency departments (Table 5).

While $56(16.8 \%)$ of the total patients are receiving hydroxycarbamide (hydroxyurea), the rest are on iron chelation treatment (single drug or combination) as shown in Table 6.

\section{Quality of medications}

$146(49.2 \%)$ of the responders reported that because of iron chelation-related side effects they had had to change chelating agent at least once in their life time. 197 patients $(59.2 \%)$ mentioned difficulty in accessing the chelating agent of their choice, while $73(21.9 \%)$ complained that the agent offered or made available to them, was not effective (based on serum ferritin levels and/or magnetic resonance imaging iron load measurements) or had side effects.

\section{New treatment options}

Patients were asked what kind of innovative treatment they would choose if they had the opportunity to do so. They were given four choices: gene therapy, agents reducing transfusion requirements, more effective iron chelation and 'others'. The responses are seen in Table 7.

Although 165 respondents (49.5\%) had a positive attitude towards gene therapy, a total of 232 patients raised concerns about gene therapy such as: i) having complications similar to bone marrow transplantation (related to myeloablation); ii) insufficient data on gene therapy complications; iii) high cost of gene therapy; and iv) other reasons mention (Table 8 ).

To the more specific question on the patients' perspectives with regards to the use of medical agents that could contribute to reduction of blood transfusion dependency, the patients responded as shown in Table 9.

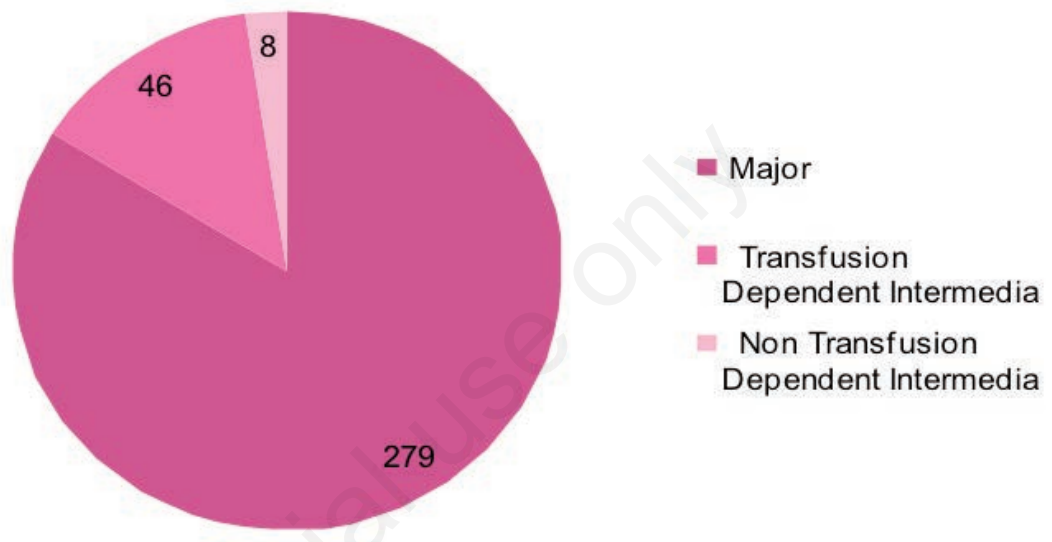

Figure 1. Types of thalassaemia among respondents. Transfusion Dependent Intermedia: Patients with thalassaemia intermedia who divert to transfusion dependency.

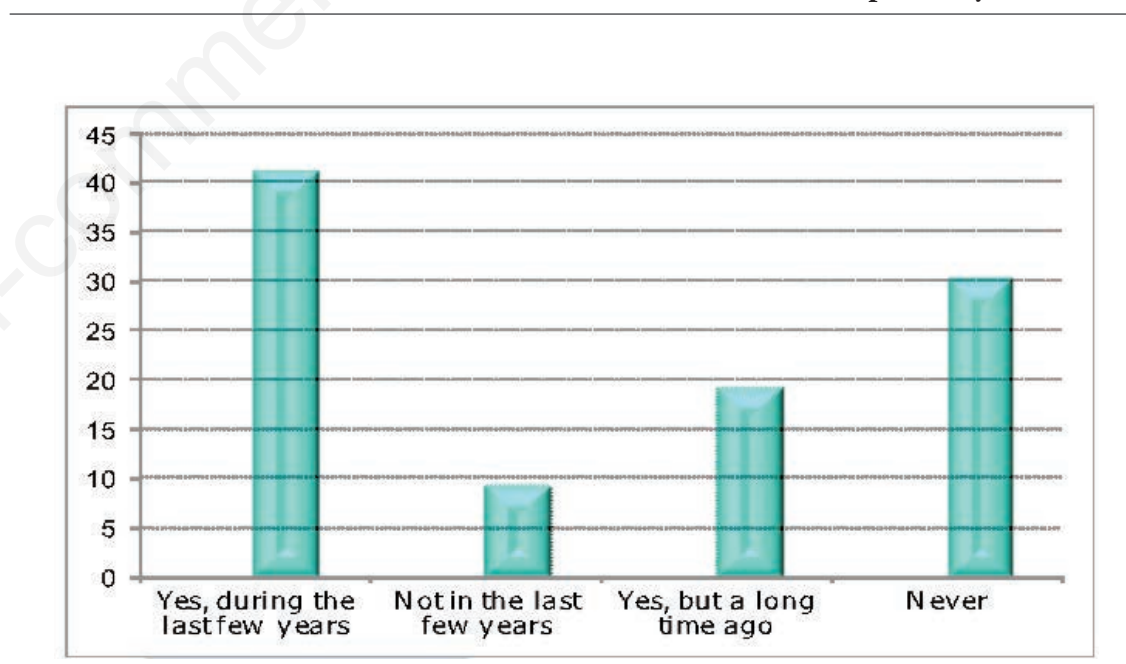

Figure 2. Blood shortage experience.

Table 1. Age.

\begin{tabular}{llcccc} 
Age & & Frequency & Percentage & Valid percentage & Cumulative percentage \\
Valid & Under 19 & 15 & 4.5 & 4.5 & 4.5 \\
& $20-29$ & 128 & 38.4 & 38.4 & 42.9 \\
& $30-39$ & 154 & 46.2 & 46.2 & 89.2 \\
& $40-49$ & 31 & 9.3 & 9.3 & 98.5 \\
& Above 50 & 5 & 1.5 & 1.5 & 100.0 \\
& Total & 333 & 100.0 & 100.0 & - \\
\hline
\end{tabular}

[Thalassemia Reports 2021; 11:9514]
$260(78.1 \%)$ of the responders expressed a positive attitude towards this approach. These agents include mainly rised recently by EMA and FDA. However, the patients also raised concerns over the future of such treatments as shown at Table some concerns were also raised as shown in Table 10. Similarly, 202 patients $(60.7 \%)$ of the
responders had a positive perspective on the se of potential new iron chelators albeit hydroxycarbamide and luspatercept, autho-

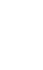




\section{Patient experience with adequacy of} blood supplies

The patient responses to blood adequacy, as this is defined in International Guidelines fall into two main categories as shown in Figure 2.

Almost half, i.e. 137 (41.4\%) and nearly a third of the responding patients complained of blood inadequacy and of no observed shortages at all respectively dur- ing the recent years.

Some key correlations related to the patients' attitude towards accepting/adopting innovative therapies.

\section{Findings}

- The findings demonstrate that there is a significant relationship between the personal experience of the patients with regards to facilitated procedures, safety and adequacy of blood, appropriately processed and stored blood, transfusion-related adverse events and their attitude to adopting innovative treatments; correlation is significant at the 0.05 level (2-tailed).

There was no significant relationship between the chelating agent used and the decision concerning the adoption of new therapies; correlation is not signifi-

Table 2. Education.

\begin{tabular}{|c|c|c|c|c|c|}
\hline \multicolumn{2}{|c|}{ Education } & Frequency & Percentage & Valid percentage & Cumulative percentage \\
\hline \multirow[t]{8}{*}{ Valid } & No school education & 8 & 2.4 & 2.4 & 2.4 \\
\hline & Under high school education & 62 & 18.6 & 18.6 & 21.0 \\
\hline & High school diploma & 120 & 36.0 & 36.0 & 57.1 \\
\hline & Associate degree & 35 & 10.5 & 10.5 & 67.6 \\
\hline & Bachelor & 78 & 23.4 & 23.4 & 91.0 \\
\hline & Master degree & 24 & 7.2 & 7.2 & 98.2 \\
\hline & Above Master degree & 6 & 1.8 & 1.8 & 100.0 \\
\hline & Total & 333 & 100.0 & 100.0 & - \\
\hline
\end{tabular}

Table 3. Type of red cells provided.

\begin{tabular}{|c|c|c|c|c|c|}
\hline & Type & $\begin{array}{l}\text { red cells (RB } \\
\text { Frequency }\end{array}$ & $\begin{array}{l}\text { provided } \\
\text { Percentage }\end{array}$ & Valid percentage & Cumulative percentage \\
\hline Valid & $\begin{array}{l}\text { - } \quad \text { Packed RBCs } \\
\text { - } \quad \text { Washed RBCs } \\
\text { - } \quad \text { Leukocyte reduced RBCs using a bedside filter } \\
1 \& 24 \\
1 \& 339 \\
2 \& 320 \\
\text { Total } 332\end{array}$ & $\begin{array}{c}83 \\
58 \\
128 \\
1.2 \\
11.7 \\
6.0 \\
99.7\end{array}$ & $\begin{array}{c}24.9 \\
17.4 \\
38.4 \\
1.2 \\
11.7 \\
6.0 \\
100.0\end{array}$ & $\begin{array}{c}25.0 \\
17.5 \\
38.6 \\
82.2 \\
94.0 \\
100.0 \\
-\end{array}$ & $\begin{array}{l}25.0 \\
42.5 \\
81.0\end{array}$ \\
\hline Missing & System & 1 & .3 & - & - \\
\hline Total & 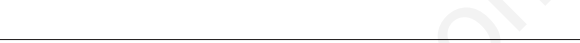 & 333 & 100.0 & - & - \\
\hline
\end{tabular}

Table 4. Frequency and severity of transfusion reactions.

\begin{tabular}{|c|c|c|c|c|c|}
\hline & & cy and seve & f transfusio & tions & \\
\hline & & Frequency & Percentage & Valid percentage & Cumulative percentage \\
\hline Valid & - Very Intense & 25 & 7.5 & 11.5 & 11.5 \\
\hline & - Intense & 33 & 9.9 & 15.1 & 26.6 \\
\hline & - Moderate & 74 & 22.2 & 33.9 & 60.6 \\
\hline & - Mild & 30 & 9.0 & 13.8 & 74.3 \\
\hline & - Very mild & 18 & 5.4 & 8.3 & 82.6 \\
\hline & $1 \& 25$ & 1.5 & $\begin{array}{l}.7 \\
2.3\end{array}$ & 84.9 & \\
\hline & $1 \& 31$ & 0.3 & 0.5 & 85.3 & \\
\hline & $1 \& 41$ & 0.3 & 0.5 & 85.8 & \\
\hline & $2 \& 38$ & 2.4 & 3.7 & 89.4 & \\
\hline & $2 \& 51$ & 0.3 & 0.5 & 89.9 & \\
\hline & $3 \& 411$ & 3.3 & 5.0 & 95.0 & \\
\hline & $4 \& 52$ & 0.6 & 0.9 & 95.9 & \\
\hline & $1 \& 2 \& 3$ & 3 & 0.9 & 1.4 & 97.2 \\
\hline & $2 \& 3 \& 4$ & 4 & 1.2 & 1.8 & 99.1 \\
\hline & $1 \& 2 \& 3 \& 4$ & 1 & 0.3 & 0.5 & 99.5 \\
\hline & $2 \& 3 \& 4 \& 5$ & 1 & 0.3 & 0.5 & 100.0 \\
\hline & Total 218 & 65.5 & 100.0 & - & \\
\hline Missing & System & 115 & 34.5 & - & - \\
\hline Total & & 333 & 100.0 & - & - \\
\hline
\end{tabular}


Table 5. Blood transfusion facilities.

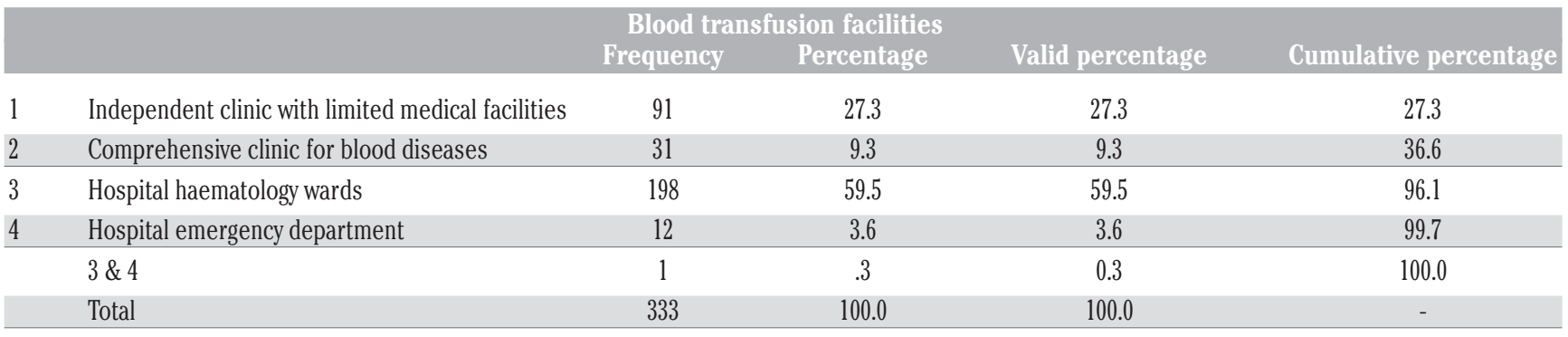

Table 6. Types of iron chelation drugs.

\begin{tabular}{llcccc} 
& & Blood transfusion facilities & & \\
Frequency & Percentage & Valid percentage & Cumulative percentage \\
Valid & - Deferoxamine injection & 97 & 29.1 & 29.1 & 29.1 \\
& $\bullet$ & 72 & 21.6 & 21.6 & 50.8 \\
& - Oral deferasirox tablets & 75 & 22.5 & 22.5 & 7.2 \\
$1 \& 2$ & 24 & 7.2 & 18.0 & 80.5 \\
$1 \& 3$ & 60 & 18.0 & 0.9 & 98.5 \\
$2 \& 3$ & 3 & 0.9 & 0.6 & 99.4 \\
$1 \& 2 \& 3$ & 2 & 0.6 & 100.0 & 100.0 \\
Total & 333 & 100.0 & & - \\
\hline
\end{tabular}

Table 7. Types of treatment.

\begin{tabular}{|c|c|c|c|c|c|}
\hline & & Type & reatment & & \\
\hline & & Frequency & Percentage & Valid percentage & Cumulative percentage \\
\hline Valid & - Permanent treatment such as gene therapy & 83 & 24.9 & 24.9 & 24.9 \\
\hline & - An alternative that would reduce their blood & 46 & 138 & 138 & 387 \\
\hline & - More effective iron chelation therapies with & & & & \\
\hline & less side effects & 44 & 13.2 & 13.2 & 52.0 \\
\hline & Other & 17 & 5.1 & 5.1 & 57.1 \\
\hline & $1 \& 2$ & 22 & 6.6 & 6.6 & 63.7 \\
\hline & $1 \& 3$ & 21 & 6.3 & 6.3 & 70.0 \\
\hline & $1 \& 4$ & 4 & 1.2 & 1.2 & 71.2 \\
\hline & $2 \& 3$ & 42 & 12.6 & 12.6 & 83.8 \\
\hline & $2 \& 4$ & 1 & 0.3 & 0.3 & 84.1 \\
\hline & $1 \& 2 \& 3$ & 40 & 12.0 & 12.0 & 96.1 \\
\hline & $1 \& 2 \& 4$ & 1 & 0.3 & 0.3 & 96.4 \\
\hline & $2 \& 3 \& 4$ & 3 & 0.9 & 0.9 & 97.3 \\
\hline & $1 \& 2 \& 3 \& 4$ & 9 & 2.7 & 2.7 & 100.0 \\
\hline & Total & 333 & 100.0 & 100.0 & - \\
\hline
\end{tabular}

Table 8. Concerns expressed about gene therapy.

\begin{tabular}{|c|c|c|c|c|c|}
\hline \multicolumn{6}{|c|}{ Concerns expressed about gene therapy } \\
\hline & & Frequency & Percentage & Valid percentage & Cumulative percentage \\
\hline \multirow[t]{12}{*}{ Valid } & $\begin{array}{l}\text { - I am afraid of its side effects because } \\
\text { it is similar to bone marrow transplantation }\end{array}$ & 21 & 6.3 & 9.1 & 9.1 \\
\hline & $\begin{array}{l}\text { - I am afraid of its side effects because } \\
\text { I don't have sufficient information }\end{array}$ & 47 & 14.1 & 20.3 & 29.3 \\
\hline & - I don't think I can afford it & 65 & 19.5 & 28.0 & 57.3 \\
\hline & - Other reasons & 14 & 4.2 & 6.0 & 63.4 \\
\hline & $1 \& 2$ & 10 & 3.0 & 4.3 & 67.7 \\
\hline & $1 \& 3$ & 10 & 3.0 & 4.3 & 72.0 \\
\hline & $2 \& 3$ & 45 & 13.5 & 19.4 & 91.4 \\
\hline & $3 \& 4$ & 2 & 0.6 & 0.9 & 92.2 \\
\hline & $1 \& 2 \& 3$ & 11 & 3.3 & 4.7 & 97.0 \\
\hline & $2 \& 3 \& 4$ & 4 & 1.2 & 1.7 & 98.7 \\
\hline & $1 \& 2 \& 3 \& 4$ & 3 & 0.9 & 1.3 & 100.0 \\
\hline & Total & 232 & 69.7 & 100.0 & - \\
\hline Missing & System & 101 & 30.3 & - & - \\
\hline Total & & 333 & 100.0 & - & - \\
\hline
\end{tabular}


cant higher than 0.05 level (2-tailed).

- The relationship between the development of thalassaemia complications i.e., medical co-morbidities and the decision to adopt new treatments was found to be significant; correlation is significant at the 0.01 level (2-tailed).

- The acceptability of new treatments had no significant relationship with education level; correlation is not significant higher than 0.05 level (2-tailed).

- The experience of hydroxycarbamide use was shown to be significantly correlated with their preference to use inno- vative medicines that contribute to decreasing transfusion dependence; the correlation is significant at the 0.05 level (2-tailed).

- There is a statistically significant difference for the future choice of treatment between male and female; the correlation is significant at 0.01 level (2tailed).

- However, there is no significant correlation between the treatment centre used by the patients, their chelation regimen or their co-morbidities and their attitude towards using potential new chelators.

\section{Discussion}

Science has provided in very recent years important 'weapons' for the management and cure of thalassaemia and sickle cell disease (SCD): an innovative drug approved by $\mathrm{EMA}^{7}$ and FDA -luspatercept used in clinical trials- promises to reduce transfusion dependency to various levels on different patients based, mainly but not confined to the patients' genetic severity and Zynteglo $^{8}$ (LentiGlobin BB305) which based on eligibility criteria and other parameters, promises the total cure (includ-

Table 9. Concerns raised about the use of alternative therapies.

\begin{tabular}{|c|c|c|c|c|c|}
\hline & Concerns raised ab & it the us & f alternative & apies & \\
\hline & & equency & Percentage & Valid percentage & Cumulative percentage \\
\hline Valid & - I do not have a good experience with hydroxycarbamide & 10 & 3.0 & 6.5 & 6.5 \\
\hline & - I have no problems with blood transfusions & 18 & 5.4 & 11.7 & 18.2 \\
\hline & - I am worried about the side effects of the drug & 28 & 8.4 & 18.2 & 36.4 \\
\hline & - I don't think I can afford it & 34 & 10.2 & 22.1 & 58.4 \\
\hline & - Other reasons & 12 & 3.6 & 7.8 & 66.2 \\
\hline & $1 \& 2$ & 1 & 0.3 & 0.6 & 66.9 \\
\hline & $1 \& 3$ & 5 & 1.5 & 3.2 & 70.1 \\
\hline & $1 \& 4$ & 4 & 1.2 & 2.6 & 72.7 \\
\hline & $2 \& 3$ & 2 & 0.6 & 1.3 & 74.0 \\
\hline & $2 \& 4$ & 2 & 0.6 & 1.3 & 75.3 \\
\hline & $2 \& 5$ & 2 & 0.6 & 1.3 & 76.6 \\
\hline & $3 \& 4$ & 18 & 5.4 & 11.7 & 88.3 \\
\hline & $3 \& 5$ & 1 & 0.3 & 0.6 & 89.0 \\
\hline & $1 \& 3 \& 4$ & 5 & 1.5 & 3.2 & 92.2 \\
\hline & $2 \& 3 \& 4$ & 4 & 1.2 & 2.6 & 94.8 \\
\hline & $3 \& 4 \& 5$ & 5 & 1.5 & 3.2 & 98.1 \\
\hline & $1 \& 2 \& 3 \& 4$ & 2 & 0.6 & 1.3 & 99.4 \\
\hline & $1 \& 2 \& 3 \& 4 \& 5$ & 1 & 0.3 & 0.6 & 100.0 \\
\hline & Total & 154 & 46.2 & 100.0 & - \\
\hline Missing & System & 179 & 53.8 & - & - \\
\hline Total & 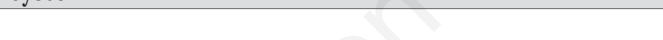 & 333 & 100.0 & - & - \\
\hline
\end{tabular}

Table 10. Concerns raised about the use of new iron chelation treatment.

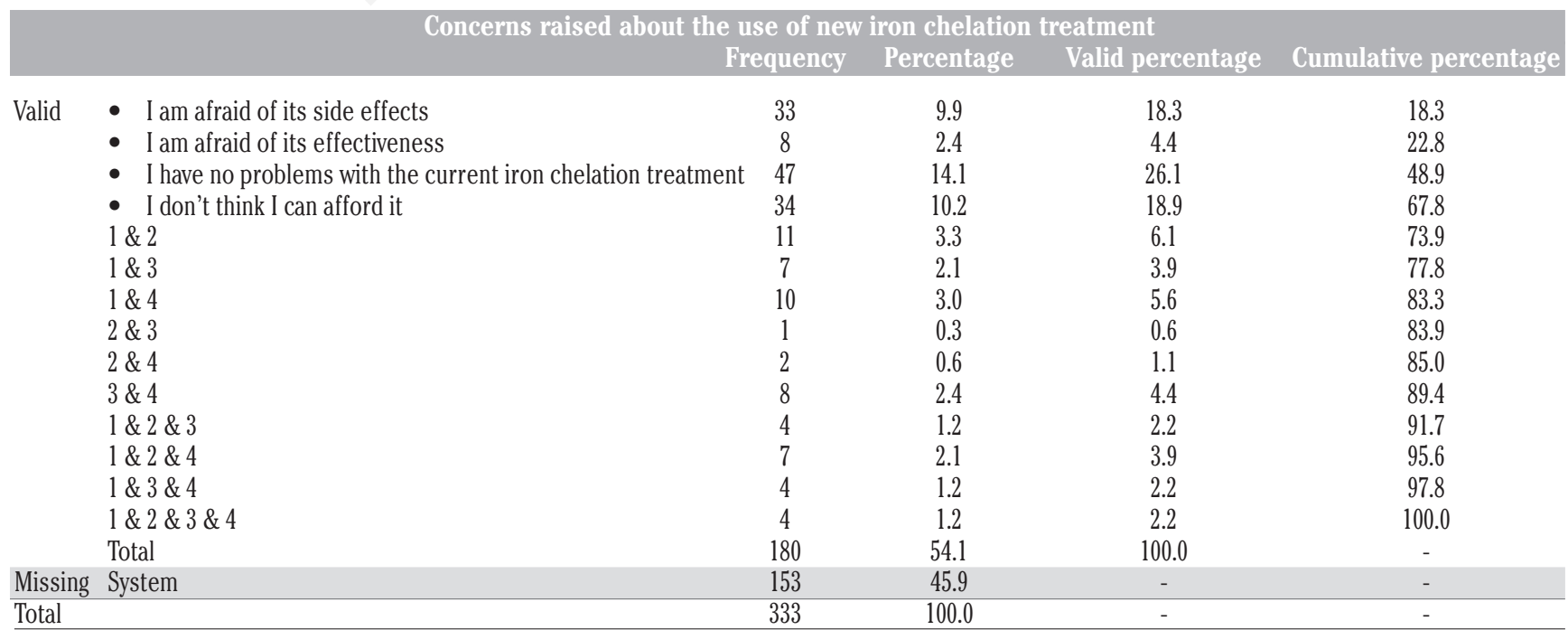


ing transfusion independency) of this disorder and soon for SCD as well.

In addition, a number of other drugs and genetic approaches for both management and cure of these disorders are well on the way with some of those in advanced clinical phases. Reliable knowledge and the patients' perspective on the use of these, is very important to be sought and obtained, both by Patient Organisations, health care professionals and very importantly by the industry and the decision makers, who (the latter) after all, will be requested to pay and make these innovative therapies accessible and available, as far as possible, to every eligible patient in need.

This survey reflects very efficiently that patients' perspective on the use of these therapies in Iran. Thalassaemia International Federation (TIF) has conducted a similar survey for patients across the world, the results of which will be shortly published.

Based on the findings of this research, the age distribution of the participants is compatible with that of the total Iranian population of thalassaemia patients. ${ }^{3}$ Thus, the survey responses can be considered to reflect the perspective of the total patient population in Iran. Nonetheless, the participation of women in the present study was significantly higher than the percentage of women in the female patient population in Iran.

The high unemployment rate in the survey participants may constitute an important reason for adopting a more negative attitude towards treatment changes that are related to high costs. The social problems faced by patients as well as their health status, are demonstrated in this survey to constitute important factors in their decision regarding their future choices for treatment.

Interestingly, about $50 \%$ of participants had a positive view of gene therapy albeit at the same time there is an expressed concern over the complexity of the gene therapy process, the complications that are related to the myeloablation part of the procedure ${ }^{9}$ and certainly its very high cost.

Regarding these concerns, it is clear that more patient oriented awareness and education are needed. The concern over the high cost of gene therapy requires further study to compare appropriately the cost of lifelong treatment versus cure through gene therapy. This exercise perhaps should be adopted in all countries so as to more accurately assess the national disease burden impacted by haemoglobin disorders in order for Governments to better acknowledge the need to adopt new, innovative curative approaches.

Similarly, the concern over medicines decreasing transfusion dependence which also pertains to cost and complications reflects the lack of sufficient information dissemination regarding both the efficacy and the complications of these medicines. Moreover, it is appropriate that a more affordable, for each region, price of these medicines should be achieved particularly in view of the large patient population in the Middle East region including Iran. This is where a regional, and not a global, collaboration such as the initiative recently launched by TIF through the International Forum on ACCessibility, Effectiveness and Sustainability of Therapie $S$ for Haemoglobin Disorders (TIF.ACCESS) Programme is important. ${ }^{10}$

The same concern exists for potential new chelators as far as patients' attitudes are concerned. The main patient concern in Iran is access to original brand medicines ${ }^{3}$ and this certainly affects their attitude in this regard. Transfusion dependence, age, gender, and occurrence of secondary complications in thalassaemia are considered to be the factors that have a significant effect on the decisions of the patients to accept innovative therapies, while other factors, such as the use of hydroxycarbamide, the type of treatment centre, and the recorded change in the type of chelators due to past complications, have had no significant impact on the patient decisions. The whole analysis shows that patients' attitudes towards the acceptability of future treatments in societies such as Iran is intertwined with complicated economic problems and does not follow a clear and integrated set of principles.

\section{Conclusions}

The findings of this research clearly shows that in order to have the true patient perspective on future choice of treatment, reliable and targeted education and comprehensive and reliable description of the pros and cons of the new treatments is needed. Further strength of advocacy skills of patients is needed in collaboration with health care professionals who will give appropriate and reliable information to patients and advise/guide them to more effectively make their choices. Moreover, the cost of new treatment choices particularly in developing economies should be based on their financial capacity so as to strengthen the access of patients to and the availability of these drugs to every patient in need or who chooses to take them.

It should be emphasized that in a society with high unemployment rate with consequent huge social challenges, the decision of patients to adopt a new treatment is great- ly influenced and that informal decision by patients on new treatments requires continued awareness and education.

\section{References}

1. Miri M, Tabrizi Namini M, Hadipour Dehshal M, et al. Thalassemia in Iran in last twenty years: the carrier rates and the births trend. IJBC 2013;6:11-7.

2. Pourfathollah AA, Hadipour Dehshal M. Thalassaemia in Iran: thalassaemia prevention and blood adequacy for thalassaemia treatment. VOXS 2019;14:114-8.

3. Hadipour Dehshal M, Tabrizi Namini M, Hantoushzadeh R, Yousefi Darestani S. $\beta$-Thalassemia in Iran: things everyone needs to know about this disease. Hemoglobin 2019;43:166-73.

4. Hadipour Dehshal M, Ahmadvand A, Yousefi Darestani S, et al. Secular trends in the national and provincial births of new thalassemia cases in Iran From 2001 to 2006. Hemoglobin 2013;37:124-37.

5. Food and Drug Administration. FDA approves first therapy to treat patients with rare blood disorder. FDA News Release. Avalable from: https ://ww w.fda.gov/news events/press-announcements/fdaapproves-first-therapy-treat-patientsrare-blood-disorder Accessed: 13 November 2020.

6. U.S. Gene Therapy Trial for Thalassemia Receives FDA Approval. Cooley's Anemia Foundation. Available from: https://www.thalassemia.org/u-sgene-therapy-trial-for-thalassemiareceives-fda-approval-2/ Accessed: 13 November 2020.

7. Bristol Myers Squibb. European Commission Approves Reblozyl (luspatercept) for the treatment of transfusiondependent anemia in adult patients with myelodysplastic syndromes or beta thalassemia. Available from: https://news.bms.com/news/details/202 0/European-Commission-ApprovesReblozyl-luspatercept-for-theTreatment-of-Transfusion-DependentAnemia-in-Adult-Patients-withMyelodysplastic-Syndromes-or-BetaThalassemia/default.aspx Accessed: 13 November 2020.

8. Bluebird bio (Switzerland) GmbH website. Help them let go of chronic transfusions. Available from: https://www.zynteglo.eu/ Accessed: 13 November 2020.

9. Anurathapan U, Pakakasama S, Mekjaruskul P, et al. Outcomes of tha- 
lassemia patients undergoing Transplant 2024;20:12.

hematopoietic stem cell transplantation by using a standard myeloablative versus a novel reduced-toxicity conditioning regimen according to a new risk stratification. Biol Blood Marrow
10. Thalassaemia International Federation website. TIF.ACCESS: A Global TIF Initiative for the promotion of the availability \& accessibility of innovative therapies. Available from: https://thalas- saemia.org.cy/news/tif-access-a-globaltif-initiative-for-the-promotion-of-theavailability-accessibility-of-innovativetherapies/ Accessed: 13 November 2020. 